to regret that he appears to view with suspicion the competency of the scientific department of the Fishery Board to try it. Perhaps it may serve to reassure him on this point to learn that these suspicions are not in any way shared by the Government, who have now furnished the means for purchasing a steam-vessel for trawling; for maintaining three laboratories (one of them with a large number of tanks); and for securing the assistance of three skilled naturalists who will work in conjunction with Profs. Ewart and McIntosh, to whom your contributor alludes.

S. F. B,

\section{Protective Influence of Black Colour from Light and Heat}

THE difficulty of explaining the black colour of races near the Equator has long been felt. Strong sunshine undoubtedly tends to darken the skin ; but if black, as generally supposed, is the colour that absorbs most heat, natural selection should have developed white as the complexion best adapted to shield mankind from the intense radiation of an equatorial sun.

Without venturing to offer an opinion on the subject, I should like to mention three cases that have come under my personal observation, in which brown-skinned natives, in very different parts of the world, blacken their faces to protect them from intense light and heat.

In Morocco, and all along the north of Africa, the inhabitants blacken themselves round the eyes to avert ophthalmia from the glare off hot sand.

In Fiji the natives, who are in the habit of painting their faces with red and white stripes as an ornament, invariably blacken them when they go out fishing on the reef in the full glare of the sun.

Lastly, here in the Sikkim hills the natives blacken themselves round the eyes with charcoal to palliate the glare of a tropical sun on newly fallen snow.

This I had an opportunity of experimenting on. We were caught in a snowstorm at an elevation of I0,000 feet; when it subsided all the coolies blackened their eyes, so I had one eye blackened, the other left natural, and went out into the sun for half an hour. I cannot say that I felt much difference. Next day I tried marching for about six hours, up to I 2 , ooo feet, with both eyes blackened. I cannot say how far this may have been palliative, but the glare was so bad, we were all very glad when the mist came up and obscured the sun. Racliation is far more intense at high altitudes than at low levels. Still it is impossible to suppose that three such different nations would have adopted the same device to mitigate sun glare if black colour did not give some palliation at least.

Here then we have one of those strange anomalies in which physiological experience contradicts the teachings of pure physics. Charcoal black, which is used in physical experiments as the best absorbent of every lind of heat radiation, is practically used by three races at least, to protect one of the most sensitive human organs from reflected light and heat. Of course I cannot offer any explanation, but bring the facts to the notice of those who have the skill and opportunity to make physiological experiments, in the hope that they may perhaps find a clue to the long-sought-for explanation of the colours of the human race.

Darjeeling, March I 5

\section{Pumice on the Cornish Coast}

ABouT a month ago I picked up on Maenporth Beach, near Falmouth, a piece of drift pumice of the size of a large goose's egg. It was rounded, floated heavily, and was just twice the weight of a piece of Krakatão pumice of the same size which had been obtained in the Indian Ocean several months after the eruption. No Cirripedes, Serpulæ, \&c., had attached themselves to it; but in one of its crevices I found a tiny dead coleopterous insect, which I unfortunately lost. From my familiarity with floating pumice in the Western Pacific I at once perceived that this fragment had been a considerable time in the water. After searching the other beaches in the neighbourhood I failed to find another piece. Mr. John Murray, to whom I sent the specimen, informs me that he has similarly picked up fragments of pumice on the west coast of Scotland.

Without speculating on the source of the fragnent found on the Cornish beach, I should remark that, judging from an experiment made in the Weitern Pacific, pumice may float for several years on the sea before it becomes sufficiently sodden to sink to the bottom. I kept floating in sea-water for two years and nine months three pieces of pumice which I originally obtained in the tow-net whilst cruising in the Solomon Islands. Although they had evidently been a long time in the water before I got them, since they floaied heavily and had in two cases the tubes of Serpulæ attached, the only apparent alteration in their buoyancy produced by my experiment was that one which floated in fresh water when I first obtained it now sank. How much longer they would have continued to float in the sea-water I cannot say. From their condition before the experiment they must have been previously floating for even a longer period.

\section{Albert Street, Regent's Park, April Io}

H. B. GuPpy

\section{The Connection between Solar and Magnetic Phenomena}

IN the discussion which followed the reading of Prof. Balfour Stewart's paper on magnetic declination, at the Physical Society, considerable weight was attached to Carrington's observation of a solar outburst observed on September I, I859, and the simultaneous occurrence of a movement of the nagnetic needles at the Kew Observatory.

Nearly twenty-seven years have now elapsed since the event referred to took place, and both the sun's surface and the magnets have been under observation thousands of hours since that time.

Hundreds of magnetic movements similar to that above mentioned have been recorded since, and I should deem it a great favour if any correspondent would either inform me of the time or time: of similar outbreaks to that seen by Carrington, if such have been observed, or refer me to any published accounts of the phenomena.

Carrington's paper is published in the Monthly Notices of the R.A.S. vol. xx. p. 13 .

Kew Observatory, April is

\section{Aurora}

A BRIGHT Polar light was observed here on March 30 from 8 to I I oclock p.m., how long it had lasted I cannot tell. At 8 o'clock only flashes of a pale blue were seen about the Pleiades; their brightness was changing very quickly; at II o'clock across the whole northern sky there lay the well-known dark segment with the bright arch above; from the latter only a few reddish beams of light were seen emerging.

Königsberg i. Preussen

H. FRITSCH

\section{Was it an Earthquake?}

YESTERDAY morning (Thursday, April 8 ), at 5.35, the door of my room vibrated regularly for about three or four seconds. I did not perceive any motion of the room itself. I was up at the time, and quite still. Perhaps the best way of finding out whether anyone else experienced anything of the same nature, so as to determine whether it was in any way connected with an earthquake, is to write to NATURE.

Ladbroke Gardens, W., April 9

\section{A. TREvor CRISPIN}

\section{"Radical" or "Radicle"}

Mr. MADAN in his amusing letter last week (p. 533) raises a point which has doubtless often caused the comments of teachers. I think "a partical of reasoning" at least $c a n$ be adduced in favour of "radical." In this paradoxical world it is not surprising to find that "radical" is the "conservative" and "constitutional "spelling, and that "radicle" is a radical alteration in a centenarian word. For next year will be the hundredth anniversary of what was, if I am not mistaken, the first use of the word by Guyton de Morveau. It seems to have long retained its French spelling, and I think it would be a pity to alter one which thus recalls to the memory a host of great names, and perhaps more than any other single word in chemistry suggests the international brotherhood of scientific men. Of course $\mathrm{Mr}$. Madan's protest has force from the grammatical point of view ; it may also be urged that "radicle" is English for the French "radical." But from the chemical standpoint surely the "radical" is as much a "stem" as a "root"? For instance toluene is either $\mathrm{C}_{6} \mathrm{H}_{5}\left(\mathrm{CH}_{3}\right)$, or $\mathrm{CH}_{3}\left(\mathrm{C}_{6} \mathrm{H}_{5}\right)$, and it would be arbitrary to select from a very limited number of reactions the "root" in prussic acid, H.CN, C.NH, or 